\title{
The Local and the Global: Hokusai's Great Wave in Contemporary Product Design Christine M. E. Guth
}

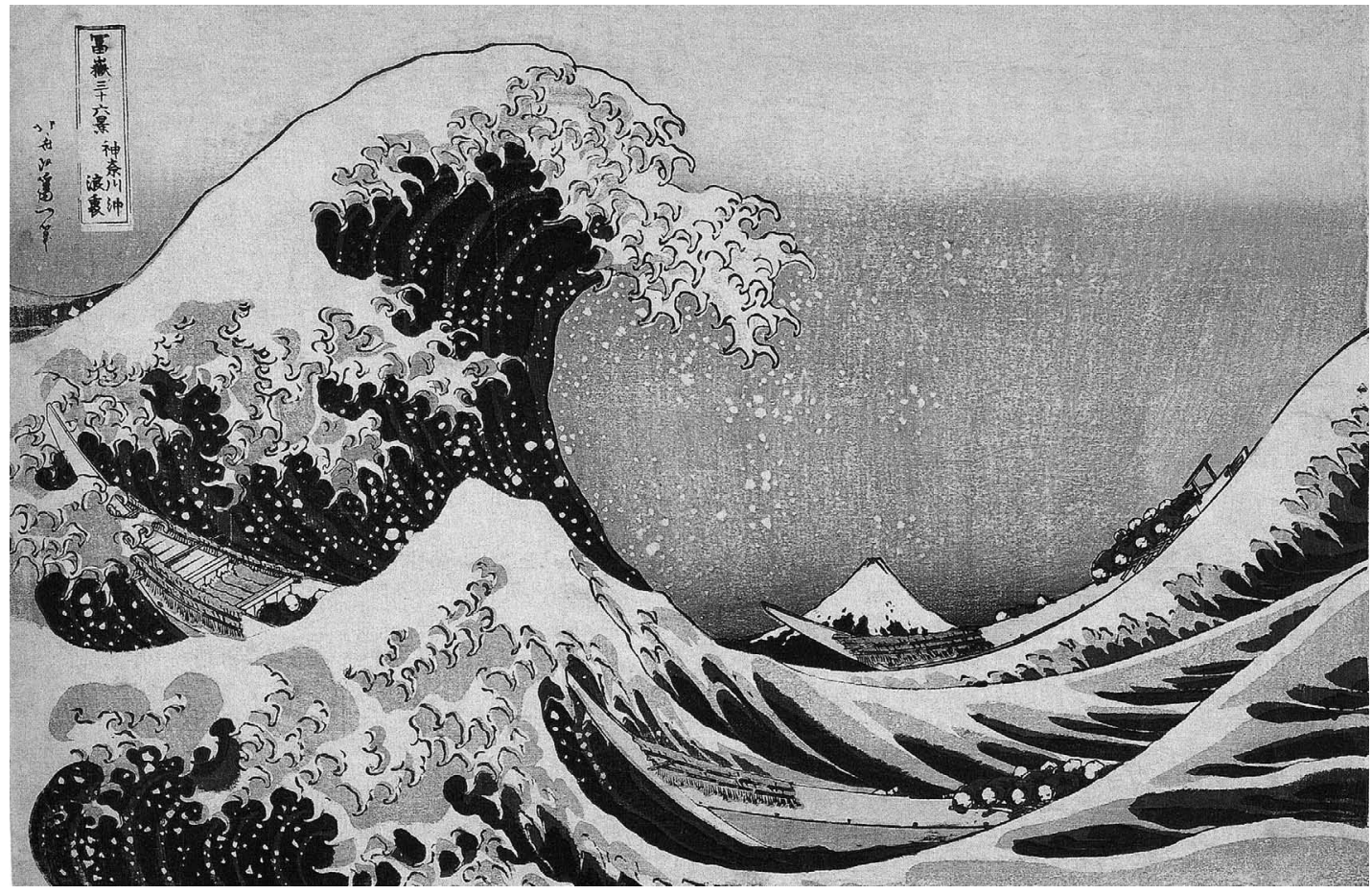

Figure 1

Katsushika Hokusai, "Under the Wave off Kanagawa," color woodcut, 1831. (B) Trustees of the British Museum.
1 On its Japanese reception history, see Christine M. E. Guth, "Hokusai's Great Waves in Nineteenth-Century Japanese Visual Culture," The Art Bulletin 93, No. 4 (December 2011): 468-85.
Hokusai's woodcut, "Under the Wave off Kanagawa" (Kanagawa oki no namiura), originally published in 1831 in the series Thirty-six Views of Mount Fuji (Fuji no sanjûrokkei), is recognized around the world. ${ }^{1}$ (Figure 1) Arguably Japan's first global brand, "The Great Wave," as it is commonly known, has been widely adapted to style and advertise merchandise, including home furnishings, clothing and accessories, beauty products, food and wine, stationery, and books. Most of the goods that trade on its celebrity status, however, are neither manufactured in Japan nor primarily dependent on the commodification of the Japanese aesthetic or locale. This essay examines the mobilization of "The Great Wave" to promote and sell mass-produced goods in the first decade of the twenty-first century, throwing light on the ways that this highly adaptive graphic design can mediate between the local and the global without necessarily referencing Japanese tradition. 


\section{A Fluid Brand Identity}

Despite the outsized visual authority it commands, "The Great Wave" does not communicate a uniform set of meanings. The motif is not popular primarily because it expresses some unique Japanese aesthetic sensibility, although desirable qualities associated with that country may be ascribed to it. Hokusai's view of a giant, white-capped, cresting wave, with three small boats struggling to cut through it, and the perfectly conical form of Mount Fuji in the distance has undeniable dramatic power, but the visual qualities that make it so compelling might be read in many, often contradictory, ways inflected by local contexts. For instance, in its country of origin it is seen as a wind-driven wave, while EuroAmerican viewers often identify it as a tsunami. Paradoxically, commercial uses of the wave for the most part encode an outlook in which it figures as a positive countervailing force to late industrial modernity, and one that can be managed through human effort. This interpretive fluidity is central to its mediating value in contemporary product design.

In her elaboration of what she calls the "productionconsumption-mediation (PCM) paradigm," design historian Grace Lees-Maffei has underscored the need to examine mediation of design objects-their marketing, advertising, and exhibitionboth synchronically and diachronically. It is important to take into account, she writes, "the degree to which mediating channels are themselves designed and therefore open to design historical analysis." ${ }^{2}$ This mediation is particularly pertinent to the study of "The Great Wave" because both designers and consumers might build differently on the symbolic complex that has cumulatively formed around it. Consequently, to assess the variety of representational practices in which it has become implicated and the effect of the meanings these practices produce on the creation, understanding, and use of the goods on which it figures today requires taking into account its reception history.

"Under the Wave off Kanagawa" originated as an inexpensive woodcut, of which some 5,000 to 8,000 impressions were issued during the artist's lifetime. Because it was a commercial product made for a popular market and not a unique work of art, in Japan it has long occupied a relatively low place in the artistic hierarchy vis à vis painting, calligraphy, and the decorative arts. The global success of anime and manga, whose enthusiasts hold Hokusai in high regard, has contributed to a reevaluation of "The Great Wave," but the image still does not enjoy the same canonical status at home as it does abroad. Its recognition as a masterpiece of world art in Europe and America is bound up with the role that Japanese woodcuts, and Hokusai's in particular, are assigned in the development of European modernism. 
Because of the Great Wave's local, non-elite origins, contemporary Japanese graphic designers have been far less enthusiastic than their Euro-American counterparts, at least domestically, about embracing Hokusai's wave for branding and marketing merchandise. The motif figures on Sony's Nintendo DS and on luggage customized by the Tokyo designer Hideo Wakamatsu. However, as these two examples illustrate, when it is used, it tends to be for goods aimed at the international market, where the design more likely carries connotations of alterity. ${ }^{3}$ Yet a niche market does exist in Japan for brand-name imports that deploy the motif. This receptivity suggests that external brand endorsement-aligned with the European propensity to see the original design as a form of high art, even if ironized-can serve to overcome any down-market stigma that might otherwise attach to the great wave. Paradoxically, when featured on fashionable foreign products, the motif becomes a marker of local distinction.

\section{Masterpiece Merchandise}

Museums are leading purveyors of Great Wave merchandise. Paper dioramas, tatebanko, are on offer at Tokyo National Museum; enameled teaspoons made in Japan are at the Guimet Museum in Paris; and paper stereoscopes manufactured in the Netherlands at the Fitzwilliam Museum, Cambridge. The British Museum has a particularly large range, including T-shirts, tea towels, plates, mugs, watches, and clocks. The Victoria and Albert (V\&A) Museum sells in its museum shop a print combining rabbits and the Great Wave, by the Japanese-American artist team, Kozyndan. The Metropolitan Museum of Art has a product line that through the years has expanded from reproductions and paper goods to include scarves, refrigerator magnets, and luggage tags. The intrinsic spectacularity of the wave gives it the agency to transform even these commonplace things into something that communicates the authority of the museum. Despite this authority, the wave remains an externally applied decoration that affects the products' perceived but not their actual performance. Igor Kopytoff has observed that when objects enter the museum, they undergo a process of "singularization" and "terminal decommoditization:" They are effectively deactivated as freely circulating commodities. ${ }^{4}$ Objects in the museum nonetheless continue to participate in the market in other ways. This process of "museumization" increases the value of analogous works still in circulation by creating unique object value. The potential for museum masterpieces to be adapted for use in the design of commercial goods further complicates this narrative. Impressions of Hokusai's "Under the Wave off Kanagawa" can be "formally decommoditized" in museums, but by their replication and adaptation in secondary forms, they "remain potential commodities."

\footnotetext{
Kopytoff, "The Cultural Biography of Things," 76.
} 
Figure 2

Peggy Lindt, "East Meets West," T-shirt design, 2004. Image courtesy Peggy Lindt.

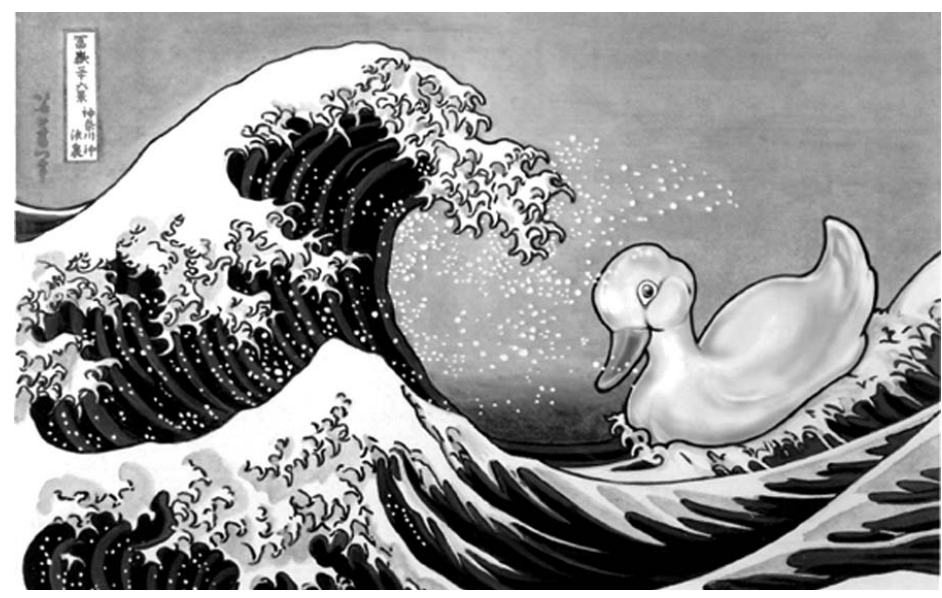

Masterpiece branding makes good commercial sense because it gives mundane mass-produced goods a cachet that distinguishes them from those available on the street. Such design, through its replication, simultaneously markets both sameness and difference. Visitors might be moved to pay more for a purchase because it reconciles consumerist impulses with good work: As all the Metropolitan Museum's packaging announces, "proceeds from the sales of all publications and reproductions are used to support the museum." A further attraction of such merchandise is its connotations of quality. Unlike other comparable articles, the quality of the museum-branded product is guaranteed not primarily by the manufacturing process, but by the internationally recognized masterpiece in the museum's collection. A pendant that advertises itself as "inspired by the V\&A collection," on sale in the Fitzwilliam Museum's shop in 2010 and online at Amazon.com, illustrates how commercial enterprises, by paying a licensing fee, can capitalize on the aura of the museum. ${ }^{6}$

Consumers' reasons for buying merchandise featuring "The Great Wave" are no doubt highly variable. The small size, practicality, and modest cost of many goods make them ideal souvenirs or gifts to mark and remember a visit to the museum. The motif might strike a chord among those with a special interest in Japan and its culture. Museums often function as alternative sites for people who are seeking but not able to have actual tourist experiences; thus, a memento bearing a striking image of the wave and Mount Fuji might appeal as a surrogate for a journey to the country. Conversely, such museum goods might also afford Japanese abroad external validation of their own culture. As waves have general connotations of travel and leisure, they also make tasteful gifts, even for those who don't visit the museum. In 2008, the Metropolitan Museum of Art was operating 23 satellite stores in major cities and airports across the United States, with the aim of catering to such travelers. ${ }^{7}$ A display at the Houston International Airport in 2007 included silk scarves and date books featuring "The Great Wave." 
The Metropolitan Museum tries to contain and restrict the circulation of "The Great Wave" by selling in its own retail stores and websites products featuring only exact reproductions (sometimes skillfully cropped for dramatic effect). However, the number of (sometimes cute or caricaturing) adaptations available from other museums has undermined the aura of exclusivity that once surrounded its merchandise. A case in point is an irreverent design by Peggy Lindt that combines two incongruous extremes of scale in a watery environment: the Great Wave and a bright yellow rubber duck. A t-shirt bearing the design was available in 2004 at the Denver Art Museum (see Figure 2). In addition, the same T-shirt could be purchased online, by anyone anywhere in the world, through Fliptomania.com. ${ }^{8}$

Today, the production and sale of masterpiece-branded goods is bound up with the global flow of capital, just as any other consumer good. Museums have extended their footprint by opening new outposts in far-away locations, and blockbuster exhibitions travel from one continent to another; not surprisingly then, museum merchandising has also become part of a vast network of material and symbolic exchange. However, these changes come at a price: these institutions can no longer maintain top-down control of their "brands."

\section{Alternative Lifestyles}

While the image of the Great Wave itself pushes the limits in its articulation or presentation of lived experience, it also delivers a visual experience that, metaphorically, may be readily translated into a bodily one. The design has undergone a wide range of reformulations in service of what B. Joseph Pine and James Gilmore have termed "the experience economy" - the commercial value of a promise by a particular product or service to provide a transformative sensorial experience. ${ }^{9}$ Many of these uses target individuals or groups that identify the wave with an alternative lifestyle. Sometimes this perception is specifically mediated by the motif's identification with Japan. Pearl River, a well-known novelty store on the periphery of New York's Chinatown, in 2007 sold bars of soap featuring the wave (without Fuji). The front of the box showed the Sino-Japanese character for eternity and the words "The Perfect Spa-water... aroma... the healing place, the unwinding place;" on the back was the explanation that the image was based on Hokusai's woodcut, "a perfect representation of a moment frozen

8 Available from http://Fliptomania.com/ in time." It interpreted its packaging for would-be consumers by explaining that "The 'eternity' symbol suggests the same idea: awareness of every moment." That the boxed soap was "Made in Australia," as indicated under its list of ingredients, speaks to the logic and reality of global production. Work is Theater and Every Business a Stage (Boston: Harvard Business School Press, 1999). 
Figure 3

Designer unknown, "The Great Wave as perceived by Mrs. Hokusai," T-shirt design. Image courtesy Anne Walthall.
10 Gennifer Weisenfeld, "From Baby's First Bath: Modern Soap and Modern Japanese Commercial Design," The Art Bulletin 86, no. 3 (September 2004): 577

11 Thorstein Veblen, The Theory of the Leisure Class (London: Unwin, 1970). Also, Pierre Bourdieu, Distinction: A Social Critique of the Judgment of Taste, trans. Richard Nice (Cambridge, MA: Harvard University Press, 1984)
Gennifer Weisenfeld, in her study of the use of a modernist aesthetic in the packaging and marketing of Kao soap in 1930s Japan, noted that one message this packaging conveyed implicitly was that, "even through a commodity as mundane as a bar of soap, every man or woman could tap into an international culture of modernism." ${ }^{10}$ Similarly, the message in The Eternal Spa's clumsy effort to manufacture authenticity appears to be the promise that, by using this product to wash, the bather can discover the natural purity and serenity that is the essence of traditional Japan. In conveying this message, it relies on a time-honored trope of Japan as an island of tranquility in the modern western world-an image strangely at odds with the disruptive potential of the wave.

Consumption, as Thorstein Veblen and Pierre Bourdieu have written, is a process of self-construction through differentiation, and marketing often capitalizes on the recognition that consumers who buy to satisfy their desires often do so with a concern for identity-but also with a need to authenticate their identity in very particular ways. ${ }^{11}$ T-shirts provide a means of achieving this end fashionably and inexpensively, and given their origins as counter-cultural apparel, they lend themselves well to adoption by those who want to assert their independence from bourgeois value systems. Both the real and the virtual marketplaces are full of entrepreneurial designers who make and market T-shirts to commemorate a special event or membership in a particular social community. Treasured as records of personal experience by those who buy them, they often take on social and cultural value beyond their modest cost.

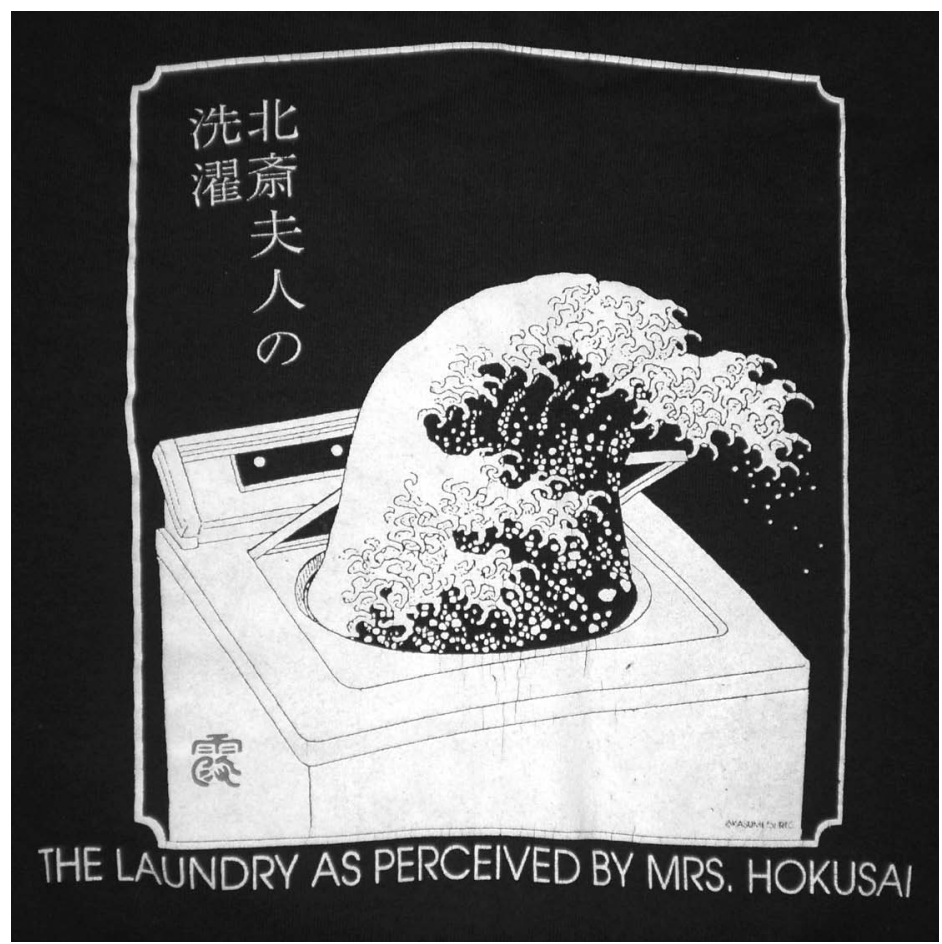




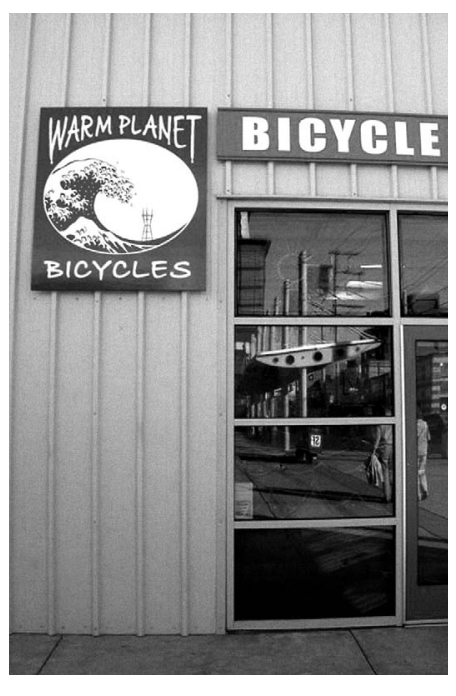

Figure 4

View of Warm Planet Bikes shop, San Francisco, California. Author's photograph.
12 Although "Kasumi for RIC" appears below the image, I have not been able to determine the identity of its creator.

13 "New Bicycle Valet Service opens at SF Caltrain Station," press release January 9, 2008 (accessed May 20, 2011).

14 Email exchange May 13, 2011.

15 Ibid.
For example, when a woman wears a T-shirt or sweatshirt that shows a great wave emerging from a top-loading washing machine, with an inscription reading, "The laundry as perceived by Mrs. Hokusai," she does not simply don an item of functional attire but makes a personal statement (see Figure 3). This shirt subverts the muscular and masculine rhetoric of the Great Wave by suggesting that, behind every great artist, there is a hard-working wife: even great artists depend on willing partners who can take care of the more (or less) mundane but necessary aspects of life..$^{12}$ Wearing clothing thus inscribed is a public act that invites reaction. In so doing, it becomes a socializing experience that might bring together those who share the outlook it expresses-or those who disagree with it.

Most pastiches of Hokusai's design, however, do not point so explicitly back to the artist or his artwork. Many professional artists and graphic designers know "Under the Wave off Kanagawa" through their studies, but such knowledge is not necessarily carried by the general public. In addition, those in the former group don't necessarily want or expect those in the latter to make the connection between their design and the original work by Hokusai.

Outdoor sports marketing fits well within already accepted understandings of waves, even as it may expand these perceptions in unpredictable, localized ways. To illustrate, in 2008, California's Bay Area leaders responded to "the growing demand for sustainable transportation choices ... amid growing concerns over global warming" by authorizing San Francisco transportation authorities to open a bicycle parking facility next to the city's main Caltrain station. ${ }^{13}$ The facility includes a repair shop and retail store operated by Warm Planet Bikes, whose logo-prominently featured on the exterior wall and decorative grills protecting the windowsis an image of a cresting wave, with Sutro Tower (a San Francisco landmark) replacing Mount Fuji in the background (see Figure 4). The logo of Warm Planet Bikes clearly doesn't speak specifically to cycling, but it evokes the Bay Area and the city where the shop is located. Underscoring the highly specific and subjective interpretation that individuals can bring to adaptations of the great wave, "Kash" - the owner-operator of Warm Planet Bikes-wrote of Sutro Tower, "it's so overwhelming that most people block it from their minds, but for me, it says 'that direction, that's where home is.'"14 He also acknowledged Hokusai as the source of his design, declaring "I rip off only the best" —an outlook that is likely shared by other creative consumers of Hokusai's "Under the Wave off Kanagawa."15 
The new creative landscape in which the Great Wave appears includes interactive "product development" that exploits consumers' desire to personalize what they wear. Zazzle, an online platform for custom products, invites consumers to take an active role in the styling of their Keds sneakers-for example, by allowing for the addition of a wide range of striking motifs. ${ }^{16}$ "The Great Wave" is one of the many artistic options this online company offers in its "remixing" of icons. The self-customization of comfortable, once inexpensive, canvas athletic shoes is achieved using computer-aided printing systems, which allow for print-ondemand products at competitive prices. Zazzle customers need only a jpg, tif, or similar image file of reasonable resolution, which in the case of the wave, Zazzle provides. Although the same wave image is used on each pair of shoes ordered with it, customers have considerable freedom to scale, crop, and place it. Thus, the process simultaneously represents mass-produced standardization and differentiation. Zazzle promotes its products using images of the customer-crafted footwear, along with the names of the designer customers; in so doing, it creates a sense of a transnational "imagined community" through consumption and design interaction. ${ }^{17}$

Who are the members of this community and what makes this design so appealing to them? Although their precise identity is difficult to pinpoint, we might assume that they include skateboarders and surfers, whose activities, like bicycling, foster a highly individualized sociability. In fact, Zazzle and other online sites also can produce Great Wave customized skateboards and surfboards. ${ }^{18}$ Once marginal, and practiced primarily in Hawaii, California, and Australia, surfing has become a global sport whose enthusiasts devote much money and attention to high-performance gear. Since 2005, for instance, customers have been able to download for the Apple Computer a "dashboard widget" styled with the Great Wave; the app is called marée (tide) and gives the tide charts for the current day, allowing users to choose from several harbors in France and elsewhere. ${ }^{19}$ However, as Marjorie Kelley has observed in a study of T-shirts in Hawaii, where modern surfing originated, "the vast majority of surf-related merchandise is sold to those who only empathize with this passion by surfing recreationally and by emulating the hard-core surfer's look and lifestyle." ${ }^{20}$

Sports marketing might center on young and predominantly male consumers, or to those who buy for them, but it can spill over into other demographics as well. Themed greeting cards are among the items that allow people to "participate" in the surfing lifestyle without getting their toes wet. In 2004 and again in 2006, the Art Institute of Chicago's annual holiday sales catalogues, which reach consumers across the United States, advertised an unconventional Christmas card of a surfing Santa, designed by illustrator Tom Hertzberg. Surfing also enjoys a huge following in Japan, and in an 
interesting variation of the "artistic remix," one enterprising maker of inexpensive paper summer fans capitalized both on this motif and on another celebrated Japanese brand, Hello Kitty.

Hokusai's design lends itself to these disparate uses because, by showing the huge, cresting wave in motion, it creates the illusion of overcoming gravity, nature, and time, even as it retains the threat of impending disaster. Its dynamic fluidity metaphorically expresses the freedom, grace, and agility required for any sport, while its heroic isolation is especially apt for those whose sports are more individualistic, like cyclists, skateboarders, and surfers. The Great Wave also has what might be characterized as street attitude, drawing attention through its in-your-face spectacle but at the same time keeping the beholder at bay with its implications of danger. If its identification with Japan is implicated in any of these readings, it is more for a generalized sense of anti-authoritarian alterity than for any intrinsic aesthetic or cultural traits.

\section{Corporate Products}

Both skateboarding and surfing activities were once subculture practices that expressed youthful rebellion, empowerment, and freedom from the bourgeois work ethic. Today, they retain something of this lifestyle image but also represent part of a multimillion dollar global business. The customization of Keds speaks to the way marginal or subculture groups might, through their do-ityourself bricolage, have an effect on mainstream products. ${ }^{21} \mathrm{Keds}$ sneakers were first produced in 1916, but competition from new styles of footwear, made by Nike and other manufacturers, forced the company to close in 1986. In 2002, however, the shoes made a come-back thanks to music, dance, and skateboarding. As one of the numerous publications now devoted to the subject of sneakers asserts, sneakers "moved out from the sports arena and exploded into popular culture as a fashion style which simultaneously transcend[s] race and class, yet defines who you are in today's urban tribes." ${ }^{22}$ In their return, Keds took on connotations of backto-basics retro chic, with implications of resistance to the powerful forces of global branding. The image of irresistible momentum that "The Great Wave" projects when applied to this footwear echoes the motion of the Nike Swoosh-providing commentary that is simultaneously a tribute and a parody.

With its company motto, "Let My People Go Surfing,"

21 Dick Hebdige, Sub-Culture: The Meaning of Style (London: Routledge, 1987), 102-06.

22 Sneakers: The Complete Collectors' Guide, written and designed by Unorthodox Styles (London: Thames \& Hudson, 2005), 7.

23 See GPIW TM Sign Logo T-shirt Style 51844 at www.patagonia.com (accessed June 1, 2011). 
Figure 5

Patagonia Logo. Property of Patagonia, Inc.

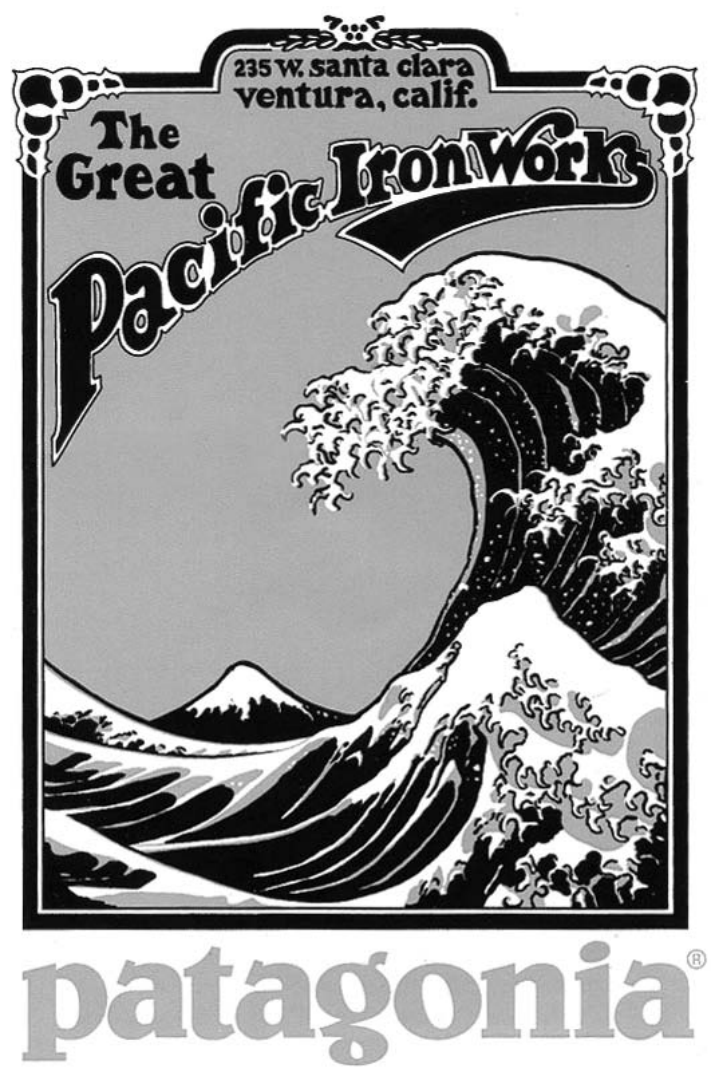

Chouinard, for both mountains and surf. ${ }^{24}$ The company began as a supplier of mountain climbing equipment, but when it moved into colorful yet practical sports clothing in 1972, this was marketed under the Patagonia label to give it a separate identity. The name Patagonia, a reference to a region in Argentina, was selected because it conveyed a romantic image of cosmopolitan ruggedness. The Japanese inflected logo, with its jagged mountain and stormy sea, reinforced this vision, while also making visible Chouinard's admiration of Japanese culture. The market in Japan for mountain climbing gear and, later, for outdoor sports clothing led the company to open shops there, and today clothing branded with Patagonia's distinctive logo has found special appeal among hip, young Japanese consumers. ${ }^{25}$

Pitching parody instead of using the straightforward "buy me" approach, and using language rich in visual and verbal quotations has worked well for Now and Zen-an Alsacian white wine sold in the United States, especially through the unconventional supermarket chain, Trader Joe's. ${ }^{26}$ The wine's unusual name is a pun on the phrase "now and then," perhaps a coy allusion to the nationwide campaign urging consumers to drink in moderation. The wine's logo is a figure in a "tipsy" rowboat perched precariously atop a playfully distorted cresting wave (see Figure 6). Now and Zen is produced in France, as suggested by the Anglophone stereotype of the French mispronunciation of the word "then;" in turn, the name links the wine to Japan through identification with 
Figure 5

Now and Zen packaging (detail).

Author's photograph.
27 Available from http://en.gigazine.net/ index.php?/news/comments/20090710_ hokusai_cream_puff/ laccessed May 31, 2011).
Zen Buddhism. The logic underlying its double-barreled branding is to convey the idea that this "wasabi white" wine is suitable for drinking with Asian fusion cuisine. This campy marketing attracts even as it distracts from the fact that the wine is a down-market product priced in 2010 at $\$ 4.99$. The label may further capitalize on Now and Zen as the title of a 1988 hit record from Led Zeppelin's Robert Plant (a connection not necessarily made, however, by all consumers). Such unconventional branding is effective, especially in the crowded global marketplace of low-cost wines. Together, the brand name and logo create the image of a hip beverage that is fun to drink. Now and Zen doesn't claim to be Japanese, but it banks on an eclectic mix of qualities that some consumers associate with that country to impart transnational distinction to its product.

The wit and marketing savvy of the distinguished Paris purveyor of gourmet foods, Fauchon, comes through in its La Vague (The Wave) éclair. Filled with quivering, creamy white goodness, La Vague's decorative icing features the Great Wave, Mount Fuji, and a single lemon yellow boat-all together also creating a visual pun on the elongated boat-like shape of the pastry itself. The unexpected conjunction of "art" and pastry serves effectively to distinguish this relatively commonplace commodity so that consumers are prepared to pay Fauchon's high prices. The wave éclair is one of a number of such customized delicacies at the gourmet shop; like Fauchon's dark chocolate Mona Lisa éclair, it capitalizes tastily, if not tastefully, on identification with an internationally recognized masterpiece. The message here is less about Japanese culture than about the global culture of conspicuous consumption of which Japan is a part. ${ }^{27}$

When or where Fauchon first introduced the éclair is not clear, but its development was likely part of a global marketing strategy to cater to Japanese consumers, both at home and abroad.

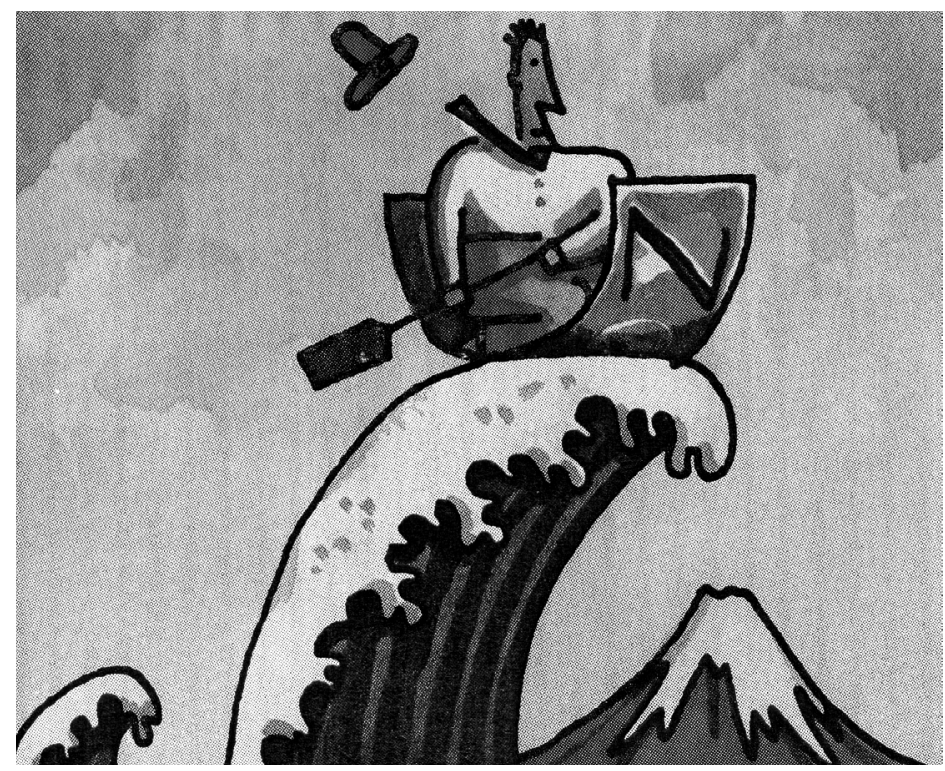

Design/ssues: Volume 28, Number 2 Spring 2012 
28 Available from http://8tokyo. com/2009/11/06/fauchon-eclair-lavague/ and http://blog.oggi.tv/ present/2010/05/fauchon.html (accessed May 31, 2011).

29 Available from Ami Kealoha, "Denim Hokusai," www.coolhunting.com/ archives/2005/10/14 (accessed June 3, 2011). Another example of promotional use of Levi's jeans is available at www.designer-daily.com/hokusaisgreat-wave-is-everywhere-4697 (accessed October 27, 2009).

30 Ibid.

31 Viviana Narotsky, "Selling the Nation: Identity and Design in 1980s Catalonia," Design Issues 25, no. 3 (Summer 2009): 68,71 .

32 Available from: http://adsoftheworld. com/media/print/Kikkoman_the_ great_wave_f_Kikkokman?size=original (accessed October 27, 2009).
Fauchon has had a presence in Japan since the 1970s and still has independent outlets there, as well as selling its confections through the up-scale Takashimaya Department Store. References to the delicacy on Japanese language blogs (where it is referred to as a dezain — the Japanese pronunciation of design-éclair) and other social networking sites suggests that it especially appeals to brandconscious young women for gift-giving. ${ }^{28}$

As part of the ocean that surrounds us, the cresting wave clearly is a motif that conveys a global message of interconnectivity that is attractive to multinational firms. In this sense it may function like the Coca Cola musical campaign based on the song, "I' $\mathrm{d}$ like to teach the world to sing," or the analogous "United Colors of Benetton" slogan, built around compelling color photographs of groups of people of disparate ethnic and racial backgrounds. In 2005, Levi's devised a campaign that played on the idea of global denim by mounting 35 pairs of blue jeans on a giant 22-foot-by-12foot canvas. Caroline Calvino, a Levi's executive and enthusiastic surfer, then painted over all of them in varying shades of blue a single giant wave alluding to Hokusai's woodcut. Called "Love and Peace," the collage was introduced at the Los Angeles fashion week before being displayed in Japan. Following the showing in Japan, 32 pairs of the exclusive jeans, each identified with the words "Love and Peace" on the back, were sent to stores in New York, London, Los Angeles, Tokyo, and San Francisco and were sold for $\$ 1,000$ each. ${ }^{29}$ By this clever ploy, Levi's disguised the commodity status of the jeans while simultaneously carrying out an act of commercial seduction. As part of the art work, the jeans were unwearable, but once dismantled, each pair was more valuable for its identification with Calvino's collage.

For Calvino, the Great Wave offered an innovative way to engage consumers around the world with Levi's product. Yet, even as her creative use of the motif brought audiences into a transnational conversation, online responses to her artwork indicate that it simultaneously drew attention to the wave's identity with Hokusai. ${ }^{30}$ In so doing, it illustrates Viviana Narotsky's assertion that a "discourse of national identity, which generally draws on pre-established cultural stereotypes, can be arbitrarily constructed 'from the outside' around certain products, reflecting the global context in which they are created and consumed rather than their intrinsic formal or 'essential' qualities."

An advertisement developed in 2008 for Kikkoman soy sauce by the Swedish division of the advertising agency, Scholz and Friends offers a further illustration of this. The ad shows a dramatic photographic close-up of the rich, amber-colored sauce splashing in the shape of Hokusai's cresting wave, and over it, the company's distinctive, hexagonal Japanese crest, with the character for 10,000 in the middle. Inscribed in small letters above the image is the tagline, "Culinary art from Japan." ${ }^{32}$ 
There is nothing intrinsically Japanese about soy sauce. It is an indispensable ingredient in all East Asian cuisines, and one that, until the surge in popularity in sushi and other "healthy" Japanese delicacies, was more likely to be associated with China. Many consumers outside the region where it was historically consumed have long used a splash of it in cooking, and brand identity is unlikely to be a major consideration in its purchase. Kikkoman is a company with a long domestic history, but since the 1970s, it has also sought to expand its international profile; thus, advertising campaigns have emphasized the fact that it is naturally brewed and fermented-an image that goes hand in hand with the perception that Japanese food is healthy. ${ }^{33}$

The advertisement described, only one of many developed for European and American consumers, trades on the stereotype of Japan as an artistic nation, and the dissemination of Hokusai's "Under the Wave off Kanagawa" that has been implicated in the creation of that stereotype since its introduction to Europe and America. However, unlike the geisha, samurai, cherry blossoms, and other motifs of Japanese origin that have become part of the idiom of modern-day Japonisme, the Great Wave has the capacity to take on a plurality of identities through its displacements to new forms and media and, in doing so, to simultaneously express and suppress cultural difference. As used by a Swedish graphic designer on behalf of a Japanese corporation that seeks to market a product whose ingredients are sourced and brewed around the world, the image can hardly be claimed to be part of an internallydriven nationalistic discourse on tradition.

\section{The Local and The Global}

This essay has sought to document, analyze, and make available for critical reflection "The Great Wave" - a graphic icon serving as a powerful cultural signifier for over a century and, for the past decade, as one deeply embedded in the language of global product design and promotion. I have necessarily been selective; no one essay can reflect the full range of commercial products and services to which the motif has been applied. The messages this icon communicates are pluralistic, ambiguous, and, like the wave itself, in a constant state of change. Nevertheless, at this point, we can reasonably ask whether there is a logic underlying the diverse products on which it appears and the messages it conveys. What can we conclude about the consumer tastes, social and economic forces, and other factors that have contributed to its ubiquity?

Does the image make visible the eastward migration of power and capital to Asia, and more specifically Japan? Might it provide coded acknowledgement of the process that sociologist Koichi Iwabuchi, in his 2002 book of the same title, described as "recentering globalization," with Japan at its center? ${ }^{34}$ The ubiquity of this graphic design can well be understood as a cultural 
phenomenon that gestures toward a value system outside Europe and America. Although the image's transnational celebrity has a long history, it has also unquestionably benefited from the global success of Japan's pop culture-animation, manga, characters, computer games, and fashion. And yet, when used as a design on or for promoting products, the great wave and its permutations are simultaneously context specific and variously situated. This multivalence argues in favor of seeing its mediating power as residing in its potential to communicate the dialectics of globalization-its decentering effects as well as its centering effects.

In discussing the reasons for the commercial success of Japanese products in China, Korea, and Southeast Asia, where there is a strong legacy of anti-Japanese sentiment, Iwabuchi underscores the absence of the "odor" of national identity in such products-a trait that he characterizes as deterritorialization: mukokuseki.$^{35}$ Might the globalizing, free-floating product identity he suggests be useful in explaining the remarkable popularity of the Great Wave as well? With its image of constant movement to, from, and between boundaries, and its implication of experience at the expense of materiality, the wave (without Mount Fuji) does seem to be emblematic of the pluralistic, fragmented, and media-saturated landscape of the postmodern world. And yet, such a reading fails to acknowledge the agency of individuals to make new social meanings for the things they see and use. The visual language and subject of the Great Wave invite the adaptation and adoption of its "deterritorializing" qualities to refer to or reflect on local socio-cultural structures, often blurring the boundaries between production and consumption. The web has been a key platform for such critical engagement, and one that has helped the motif to become a symbol of global cool. Although the Great Wave has been mobilized to confer desirable Japanese connotations on some products, today it functions increasingly as a transnational signifier of local difference. Paradoxically, the aura of alterity that it confers on the products it promotes is dependent on its status as a global icon.

\section{Acknowledgements}

I would like to thank Allen Hockley for his comments on an earlier version of this essay and, especially, Kimberley Chandler for her research assistance. 